Original Article

\title{
ANTIOXIDATIVE PROPERTIES OF SELECTED POLISH HONEYS
}

\author{
Paweł Piszcz \\ Bronisław K. Głód* \\ Department of Analytical and Inorganic Chemistry, Institute of Chemistry, Faculty \\ of Science, Siedlce University of Natural Sciences and Humanities, 3 Maja 54, \\ 08-110 Siedlce, Poland \\ *corresponding author: bkg@onet.eu \\ Received: 1 July 2018; accepted: 14 November 2018
}

\section{A B S T R A C T}

The antioxidative activities of honeys collected in Poland were screened. The total antioxidant potential (TAP) provides more information about the system than the determination of individual antioxidant. TAP is proportional to the sum of products of concentrations of all antioxidants in the sample and their antioxidant powers (rate constants). To measure, compare and correlate TAPs, we used techniques which we had recently elaborated (i) related to hydroxyl radicals, (ii) RP-HPLC measurements with amperometric detection and (iii) differential pulsed voltammetry (DPV). They were correlated with techniques already described in the literature (i) related to the DPPH radicals, (ii) the total content of phenolic compounds and (iii) color intensity. All assays revealed the following order of obtained TAP values: buckwheat > honeydew > linden > multi-flower > acacia honey. Correlations were found between results obtained using different techniques. There was also a significant correlation with the results obtained by authors using other measurement techniques. Differences in antioxidant properties among individual honeys are inversely proportional to the strength of the radicals in relation to which measurements were performed. This is due to the fact that strong radicals react not only with strong antioxidants but also with weak ones, which are much more common. The darker honeys were also observed to be characterized by higher TAP values.

Keywords: fenton reaction, free radicals, high performance liquid chromatography, honey, mead, total antioxidant potential

\section{INTRODUCTION}

Atoms, molecules or ions with an unpaired number of electrons are called free radicals (Sharan, Odyuo, \& Purkayastha, 2011). They are responsible for many diseases, aging processes and apoptosis (Raz \& Daugherty, 2018). Most of them are strong oxidants. The free radical scavengers deactivate free radicals, while antioxidants remove oxidants. Both terms are frequently used interchangeably (Elad, 1992), but generally the term antioxidant refers to any substance which at a low concentration prevents oxidation. Diseases and aging sometimes decrease the productions of antioxidants, so their depletion should be compensated by an increased antioxidant-rich food supply (Hoyos-Arbeláez, Vázquez, \& ContrerasCalderón, 2017). Exogenous antioxidant intake is crucial to maintaining a red-ox buffer and repairing and/or preventing cell damage. Free radicals have been also implicated in the deterioration of food (Smirnov, 2017). Synthetic antioxidants are widely used in the food industry and medicine. Because they are often carcinogenic and contribute to free radical production, natural antioxidants are intensively studied.

Honeys and the meads obtained from them serve as a source of natural antioxidants and are considered as functional food with physiological beneficial constituents (Junie et al., 2016). Therefore, the knowledge of the antioxidant properties of honeys and other bee-products is important in the food industry as well as for health and nutrition (Bogdanov et al., 2008). They are natural food (not processed and not contain any additives) and contain such natural antioxidants as phenolic acids, flavanoids and vitamins which prevent many diseases. Their amounts and types depend largely 
upon the floral source of honey (Wróblewska, Warakomska, \& Koter, 2006). Darker honeys have usually been shown to have a higher antioxidant content than lighter ones (Bertoncelj et al., 2007). Polyphenols because of their antiradical and antioxidative activities are believed to be important in human health for cancer and heart diseases prevention, immune system decline, gastrointestinal disorders and antiinflammatory activity (Arroyo-Curras, RosasGarcia, \& Videa, 2016). Furthermore, they have been proven to be effective against deteriorative oxidative reactions in food, caused by light, heat and some metals (Waś et al., 2017).

In the literature, many methods of the total antioxidant potential (TAP) assays are described. Other names and acronyms often include total antioxidant capacity (TAC), activity (TAA), reactivity (TAR), status (TAS) and redox antioxidant parameter (TRAP) (Głód, Czapski, \& Haddad, 2000; Masek, Chrzescijanska, \& Zaborski, 2014). There is no one universal assay capable of providing an accurate TAP value because of several mechanisms underlying TAP measurements, including electrochemical reactions, termination of free radical mediated chain reaction and chelation of catalytic transition metals ions. In addition, such side reactions as metal complexations or redox reactions are observed among radicals, antioxidants and metals. Therefore, a single method is not sufficient to describe the sample antioxidative properties and different analytical methods are utilized instead. However, natura/methods for studying the redox reactions seem to be electroanalytical ones (Głód, Kiersztyn, \& Piszcz, 2014).

Indeed, TAP has been already estimated through potentiometry or voltammetry as analytical techniques (Hoyos-Arbeláez, Vázquez, \& Contreras-Calderón, 2017; Doménech-Carbó et al., 2017; Głód, Haddad, \& Alexander, 1992; OrtizMiranda et al., 2016; Doménech-Carbó et al., 2015; Sužnjević, Pastor, \& Gorjanović, 2015). The righteous TAP measure is a standard redox potential, which is directly correlated with the half-wave potential in polarography and the voltammetric peak potential. However, this measure can be used only for pure compounds than for complex real samples, like food products (honeys). The purpose of the present study was to evaluate the total antioxidant potential (TAP) values of honeys from Poland of different botanical origin, obtained using various assays including those elaborated by us.

\section{MATERIAL AND METHODS}

\section{Instrumentation}

HPLC was measured through means of a chromatograph (comprising of an Interface Box, 4 channel Smartline Manager 5000 with Degasser K-5004, Solvent Organizer K-1500, Dynamic Mixing Chamber, HPLC Pump Smartline 1000, UV/Vis Diode Array Detector Smartline 2600, $20 \mu l$ D-14163 injection Valle and Smartline 4000 Column Thermostat; all from Knauer $\mathrm{GmbH}$, Berlin, Germany) and an amperometric detector (Recipe, Berlin, Germany, ClinLab EC3000; working electrode - glassy carbon electrode, GC; reference electrode - $\mathrm{Ag} / \mathrm{AgCl}$; auxiliary electrode - cell body) and an autosampler (Smartline-3900). Samples were separated on a Eurospher RP-18, 5 um, 250 x 4 mm I.D. (Knauer, Berlin, Germany) column. System was controlled and data acquired on an IBM PC type computer with Eurochrom 2000 and ClarityChrom V 2.62007 software. pH was measured using Ph-metr OP-208/1 (Radelkis, Budapest, Hungary) with OSH 10-10 electrode (Metron, Swiss). Photometric (total phenolic compounds content) measurements were performed with the use of a Helios Epsilon spectrophotometer (Thermo Fisher Scientific, USA) and spectrophotometer DU68 (Beckman, USA).

Electrochemical measurements were performed using the Autolab PGSTAT20 potentiostat/galvanostat (Eco Chemie, Utrecht, Netherlands). A three-electrode system was used throughout the study. As a working electrode, a $2 \mathrm{~mm}$ diameter glassy carbon disk, polished before each measurement, was used. A platinum wire served as an auxiliary electrode and saturated $\mathrm{Ag} / \mathrm{AgCl}(3 \mathrm{~mol} / \mathrm{L} \mathrm{KCl}$ ) electrode as a reference electrode. Prior to use, the GC working electrode was polished with an aqueous suspension of 0.05 $\mathrm{mm}$ alumina on a polishing pad and then rinsed 
with water. All solutions were deaerated with a stream of argon. The system was controlled and data was acquired on an IBM PC type computer with GPES v 4.9 software.

\section{Reagents}

Gallic, 3,4-dihydroxybenzoic and p-hydroxybenzoic acids, iron(II) sulfate(VI), phosphate buffered saline (PBS) tablets and HPLC grade methanol were obtained from Sigma (St. Louis, MO, USA); bromine, sodium tungstate, sodium molybdate, sodium carbonate, phosphoric acid, lithium sulfate, hydrochloric acid, sodium hydrogen phosphate and sodium dihydrogen phosphate from POCh (Gliwice, Poland); sodium hydroxide and hydrogen peroxide from CHEMPUR (Piekary Śląskie, Poland); and DPPH - 2,2-diphenyl-1-picrylhydrazyl, CSA - camphosulfonic acid (Sigma - Aldrich). Water was distilled three times from quartz. Mobile phases were filtered through a $0.22 \mu \mathrm{m}$ membrane filter (Millipore, Bedford, USA). Commercial honey types acacia, multi-flower, linden and honeydew were purchased from Bartnik Sądecki apiary and buckwheat from pasieka Władysław Jezior aрiary.

\section{Procedures}

We estimated the TAPs, related to hydroxyl radicals $\left(\mathrm{TAP}^{\mathrm{OH}}\right)$, of the honey samples, as described in our previous study (Głód et al., 2011), using a HPLC/UV system. The hydroxyl radicals were generated in the Fenton reaction (0.3\% hydrogen peroxide, a solution of $1 \mathrm{mM}$ iron (II) and phosphate buffer at pH 7.4). A chromatographic analysis of 3,4-dihydroxybenzoic was performed with a flow rate of $1.0 \mathrm{ml} / \mathrm{min}$. The column was stabilized at $20^{\circ} \mathrm{C}$ for the mobile phase for $1 \mathrm{~h}$ prior to the chromatographic measurements. A phosphate buffer (pH6.6) was used as a mobile phase. $10 \mathrm{mmol} / \mathrm{L}$ stock solutions of the analyzed compounds were prepared in triplicate distilled from quartz water and diluted to the required concentration before use. $20 \mu$ samples were injected with an autosampler.

Chromatographic experiments with electrochemical detection were performed at $1.0 \mathrm{ml} / \mathrm{min}$ flow rate. The column was stabilized at $20^{\circ} \mathrm{C}$ during the passage of the mobile phase for $1 \mathrm{~h}$ prior to the chromatographic measurements. A phosphate buffer (100 mmol/L, pH 6.6) + methanol $(96+4) \%$ v/v was used as a mobile phase. Stock solutions of the honeys were prepared in triplicate distilled from quartz water and diluted to the required concentration before use. $20 \mu$ samples were injected with an autosampler. An output signal from the electrochemical detector was continuously displayed on the computer. The measurement of the TAP value was the total surface area of all peaks recorded on the chromatogram at the given potential of working electrode.

Electrochemical measurements, differential pulse voltammetry (DPV) and cyclic voltammetry (CV), were performed using the three-electrode system consisting of a $2 \mathrm{~mm}$ glassy carbon disk, platinum wire auxiliary electrode and saturated $\mathrm{Ag} / \mathrm{AgCl}$ (3 mol/ $\mathrm{L} \mathrm{KCl}$ ) electrode as the reference electrode. Electrochemical measurements $(10 \mathrm{ml})$ were done in $100 \mathrm{mM} \mathrm{NaClO}_{4}$ as a basic electrolyte, $1 \mathrm{mM}$ camphorsulfonic acid (CSA) to protect working electrode against irreversible adsorption of the analyzed samples and $100 \mathrm{mM}$ phosphate buffer $\mathrm{pH}$ 7.4. All cyclic voltammograms were measured at positive potentials usually ranging between $0.0 \div 1.5 \mathrm{~V}$ at a scan rate of $200 \mathrm{mV} / \mathrm{s}$. DPV measurements were performed using the following parameters: pretreatment conditioning potential - $0.5 \mathrm{~V}$; equilibration time - $5 \mathrm{~s}$; measurement modulation time - 0.002 $\mathrm{s}$; interval time - $0.3 \mathrm{~s}$; initial potential $-0.5 \mathrm{~V}$; end potential - 1.5V; potential step - $4.95 \mathrm{mV}$; modulation amplitude - 0,03 V. Each sample was analyzed three times (Głód, Kiersztyn, \& Piszcz, 2014; Masek, Chrzescijanska, \& Zaborski, 2014). The DPPH free radical scavenging activity of the extracts was measured according to the photometric method (Brand-Williams, Cuvelier, \&Berset, 1995). The measurements were performed by adding to a $1 \mathrm{ml}$ glass cuvette $0.4 \mathrm{ml}$ of honey extract at a concentration $400 \mathrm{mg} / \mathrm{ml}, 0.4 \mathrm{ml}$ $\mathrm{DPPH}$ methanolic solution $(0.2 \mathrm{mmol} / \mathrm{L})$ and 0.2 $\mathrm{ml}$ water. The reaction mixture was vortexed and absorbance was measured at $517 \mathrm{~nm}$ using a spectrophotometer with methanol as the blank. Decrease in absorbance was monitored at $0 \mathrm{~min}, 1 \mathrm{~min}, 2 \mathrm{~min}$, and every $15 \mathrm{~min}$ until 
the reaction has reached a plateau. The TAPDPPH was expressed as gallic acid equivalents (GAEs = $1000 x$ mass of GA / mass of honey).

The total concentration of the polyphenols was estimated through the use of modified Folin - Ciocalteau (FC) assay (Cheung, Cheung, \& Ooi, 2003). In the reaction of polyphenols with a $\mathrm{FC}$ reagent, the blue tungsten $\left(\mathrm{W}_{8} \mathrm{O}_{23}\right)$ and molybdenum $\left(\mathrm{Mo}_{8} \mathrm{O}_{23}\right)$ oxides formed. Measurements were performed by adding to a $10 \mathrm{ml}$ flask $1 \mathrm{ml}$ of honey extract at a concentration $400 \mathrm{mg} / \mathrm{ml}$ and $1 \mathrm{ml}$ of $F C$ reagent. After three minutes, $4 \mathrm{ml}$ of $20 \% \mathrm{Na}_{2} \mathrm{CO}_{3}$ was added and supplemented with water to the mixture. In this basic state the dissociation of phenolic proton leading to a phenolic ion was capable of reducing FCR. The reaction mixture was incubated at $25^{\circ} \mathrm{C}$ for $30 \mathrm{~min}$. The absorbance was determined at $765 \mathrm{~nm}$ with a spectrophotometer. Water was used as blank. The phenolic compound concentrations were expressed as gallic acid equivalents (GAEs). The gallic acid solutions with con-

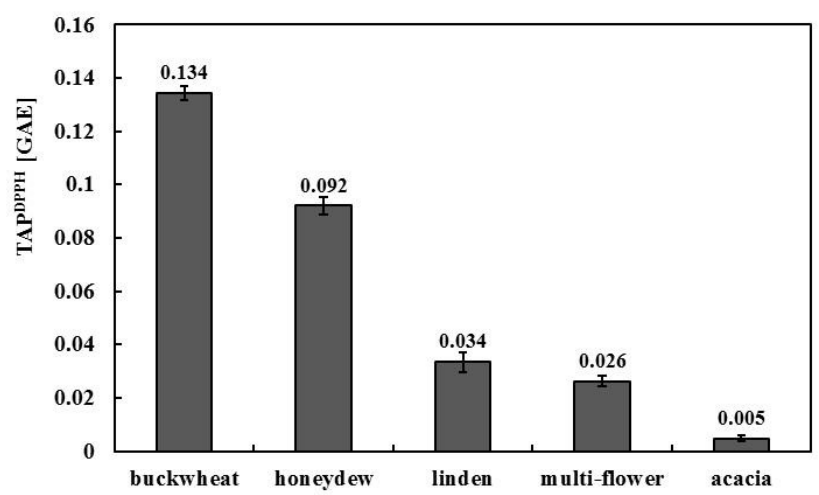

Fig. 1. TAPDPPH values of five different honeys. The results show the average $\pm S D$ of three independent experiments.

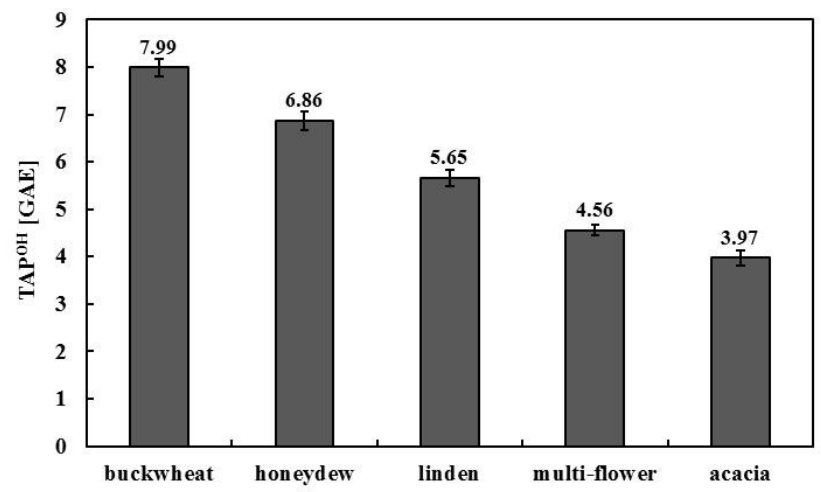

Fig. 2. TAPs ${ }^{\mathrm{OH}}$ of tested honeys. The results show the average $\pm S D$ of three independent experiments. centrations ranging from 0.1 to $8 \mu \mathrm{g} / \mathrm{l}$ were used for calibration. A dose response linear regression was generated by using the gallic acid standard absorbance and the levels in the samples were expressed as gallic acid equivalents ( $\mathrm{mg}$ of $\mathrm{GA} / \mathrm{g}$ of honey solution).

The color of honey has been suggested to reflect largly its antioxidant activity (Bertoncelj et al., 2007). Therefore, the color intensity was measured for each of the honeys, which were diluted with distilled water to $50 \%$ solution. The solution was then ultrasonicated for five minutes and filtered through a filter $(0.45 \mu \mathrm{m}$ membrane Millipore filter). The absorbance was measured at 450 and $720 \mathrm{~nm}$. The results are presented as the difference in absorbance at these two wavelengths. The honeys were prepared by being dissolved in water in the ratio 1:10 (electrochemical measurements) or 1:20 (chromatographic and photometric measurements) and filtered through $0.45 \mu \mathrm{m}$ membrane Millipore filter.

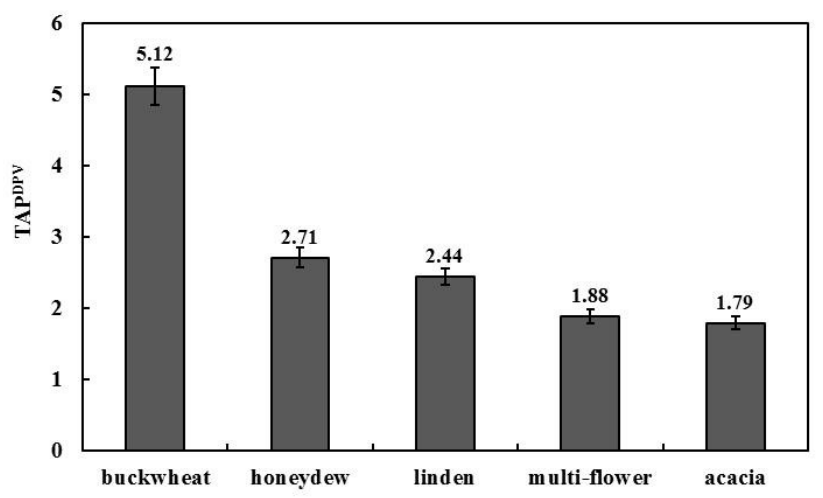

Fig. 3. TAPsDPV of tested honeys. Results show the average $\pm S D$ of three independent experiments.

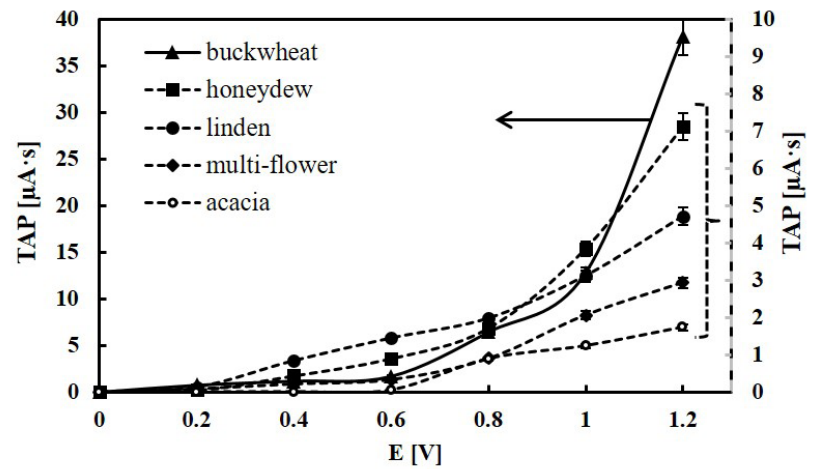

Fig. 4. TAPED values of honeys obtained at different potentials using HPLC-ED assay (by the growth: $\circ$ acacia, multi-flower, $\bullet$ linden, - honeydew, A buckwheat honeys). 

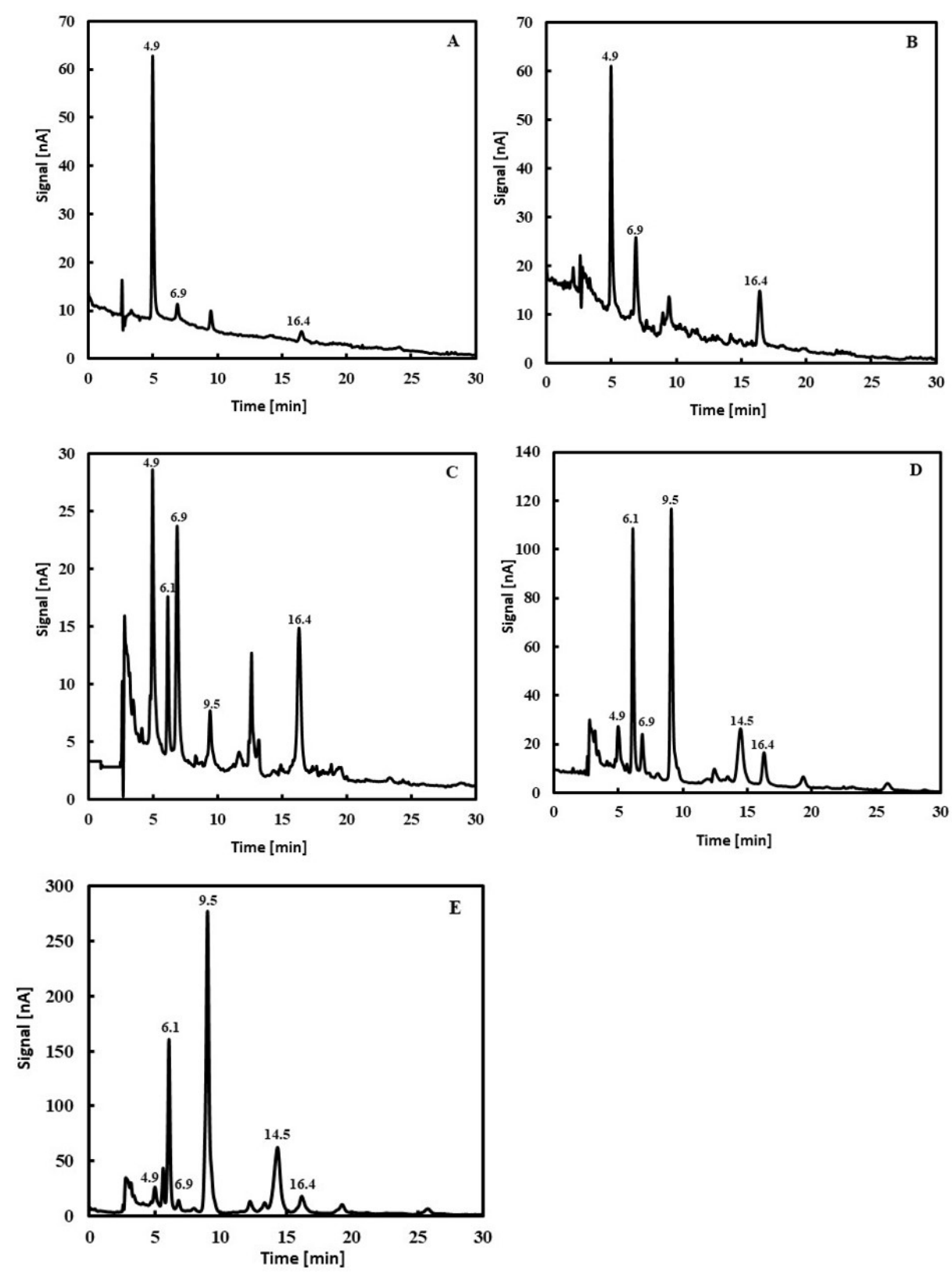

Fig. 5. HPLC chromatograms of the $1 \mathrm{mg} / \mathrm{ml}$ buckwheat honey. Electrochemical detector with the glassy carbon working at electrode potential, $E=0.2 ; 0.4 ; 0.6 ; 0.8 ; 1.0 \mathrm{~V}$ vs $\mathrm{Ag} / \mathrm{AgCl}$ for figures $A \div E$, respectively.

\section{Data Analysis}

The measurements of the antioxidant capacity were done three times for each sample and the average was used for further calculations. From such obtained results the background (without sample) TAP values were subtracted.

\section{RESULTS}

Different assays were used for the TAPs determination of five different honeys, which allowed a deeper understanding of the oxidation mechanisms. The TAP values related to the DPPH and hydroxyl radicals are presented in Figs. 1 and 2, respectively. TAPs measured using differential pulsed voltammetry are presented in Fig. 3. TAPs obtained with the use of HPLC measurements amperometrically detected at different working electrode potentials is presented in Fig. 4 and their corresponding chromatograms in Fig. 5. For comparison, the total concentration of polyphenolic compounds and color intensity of honeys are presented in Figs. 6 and 7. 


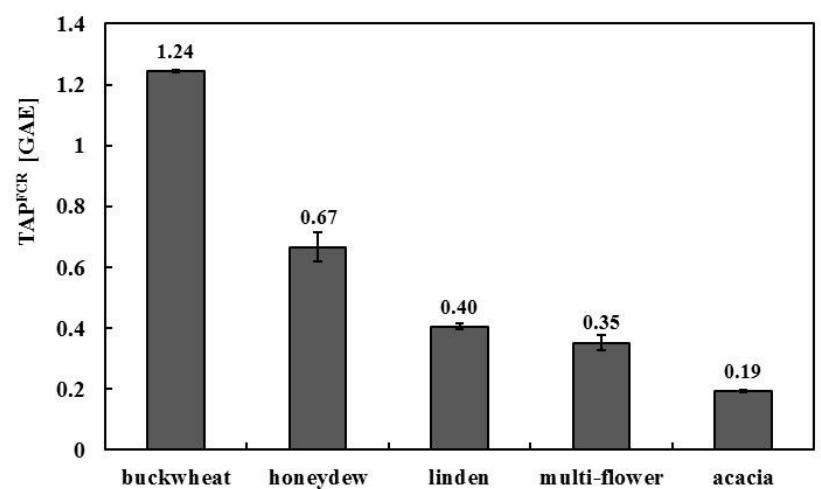

Fig. 6. Total polyphenol content of five investigated honeys.

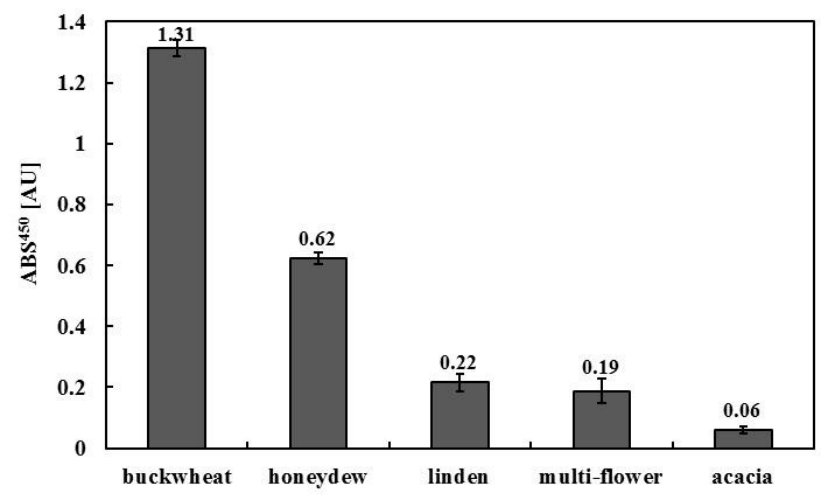

Fig. 7. The absorbance of honeys.

\section{DISCUSSION}

Several TAP measurement techniques, including those elaborated by us, are compared in the paper. The main components of honey are polyphenols, which are probably responsible for its antioxidant properties. The composition and antioxidant activity depend on the source of downloaded nectar, seasonal and environmental factors and the processing and treatment (Bertoncelj et al., 2007). Generally, more darkly colored honeys have a higher antioxidant potential (Wilczyńska, 2010).

Such polyphenols as flavonoids and phenolic acids derived from benzoic, mandelic and cinnamic acids are antioxidants commonly found in food products, including honey. Hence, their concentrations reflect the TAP of strong antioxidants of the sample. The Folin-Ciocalteu method (Brand-Williams, Cuvelier, \& Berset, 1995) was used to estimate the total phenolic content of the honeys as is presented in Fig. 6 . The FolinCiocalteu reagent is not selective only to polyphenols but also reacts with such other reducing agents as ascorbic acid (Singleton, Orthofer, \& Lamuela-Raventós, 1999). Therefore, the assay tends to overestimate the level of polyphenols. The total polyphenol content varied from 0.19 to 1.24 GAE for the tested acacia and buckwheat honeys, respectively.

A popular method for TAP determination is based on the DPPH free radical scavenging activity assay and relies on the reduction of methanolic DPPH solution in the presence of antioxidants (Piszcz et al., 2014). DPPH reduction by a hydrogen donating compound leads to a change in color. The obtained results are presented in Fig. 1. Total polyphenols content correlated with the TAPDPPH of the honeys $\left(R^{2}\right.$ $=0.946$ ) (Fig. 8.). This is in accordance with findings by authors who reported that total phenolic content correlated with the free radical scavenging activity of honeys (Pontis et al., 2014, Wilczyńska, 2010). Larger values expressed in GAE were obtained for the FC method. The relationship shown in the graph does not go through the zero. This means that some weak antioxidants did not react with the DPPH radical but were oxidized by the FC reagent.

The color intensities of the investigated honeys are shown in Fig. 7. The greatest $A_{B S}^{450}$ [AU] value is shown to be in the buckwheat honey solution and the lowest in the acacia one. The compounds carotenoids, xanthophylls, chlorophylls and flavonoids with aromatic or double bond moieties are responsible for the color of honeys (Piszcz et al., 2014; Wróblewska \& Stawiarz, 2004). In addition, the color depends on colloids formed from protein molecules, beeswax, bio-elements and water and may become darker as a result of the Maillard reaction (Antony et al., 2000). On the other hand, a feature of strong antioxidants is their many resonant (mesomeric) structures (Piszcz et al., 2014). Thus, the correlation between color and antioxidant strength is anticipated, as shown in Fig. 9.

Hydroxyl radicals are the most reactive that appear in living organisms and also among the strongest known oxidants. Their reduction potential equals 2.31 $\mathrm{V}$ versus standard hydrogen electrode. Therefore they are highly 


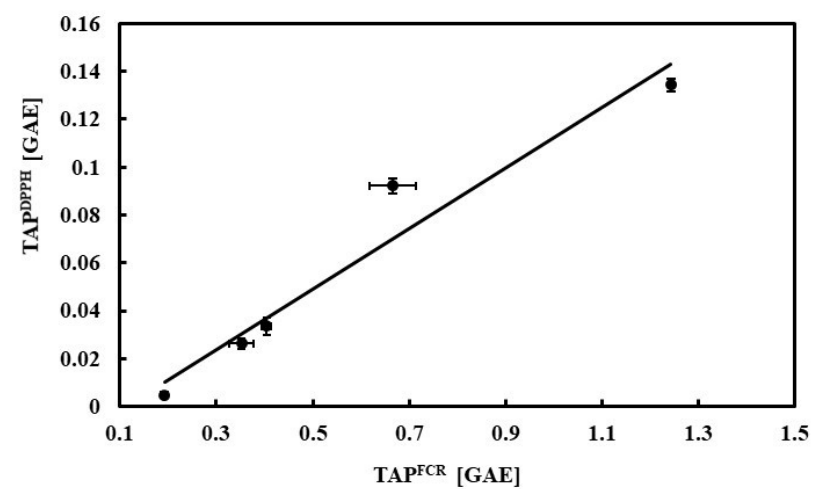

Fig. 8. The correlation between TAP(DPPH) and total polyphenol content.

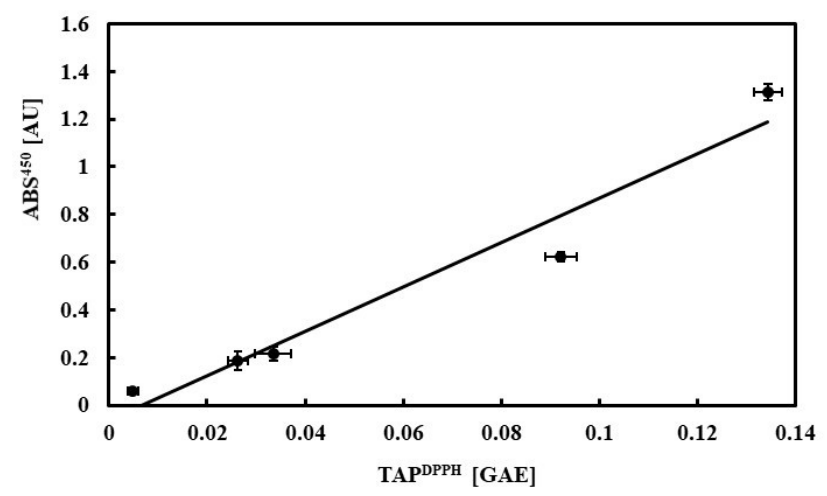

Fig. 9. The correlation between $A B S^{450}$ and TAPDPH.

reactive, so TAPOH provides more reliable information than TAPDPPH. An assay for the determination TAPOH (Piszcz, Żurawski, \& Głód, 2014) was developed based on the reaction of hydroxyl radicals, generated in the Fenton reaction, with the test sample and a spin-trap sensor, salicylic, p-hydroxybenzoic or terephthalic acid. The product of the radical reaction with the sensor is determined through HPLC photometric, fluorescence or electrochemical detection. The buckwheat was characterized by the strongest antioxidant properties (Fig. 2). Total polyphenols content (TPC) correlated to $\mathrm{TAP}^{\mathrm{OH}}\left(\mathrm{R}^{2}=0.892\right)$. This suggests that TAPs are mainly due to polyphenolic compounds (Fig. 10), although the weak correlation indicates that other antioxidants are also present in the sample. Hydroxyl radicals react not only with polyphenols but also with such compounds as alcohols or sugars. Therefore, relationship shown in the graph in Fig. 10 does not pass through the origin of coordinate system. Even without polyphenol in the sample, hydroxyl radicals react with such weak antioxidants as sugars, but also side reactions cannot be omitted.

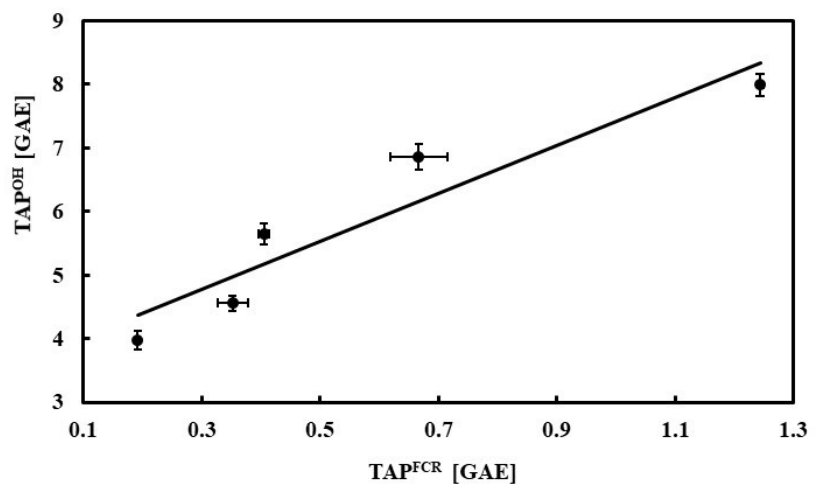

Fig. 10. Correlation between TAPOH and total polyphenol content of tested honeys by the growth of polyphenols: acacia, multi-flower, linden, honeydew, buckwheat .

The sample's ability to reduce $\mathrm{Fe}^{3+}$ ions (a prooxidant metal ion) suggests that they act as free radical chain terminators and transform reactive free radical species into more stable non-radical products, for example in ascorbic acid. On the other hand, $\mathrm{Fe}^{2+}$ is also pro-oxidant because it participates in the Fenton reaction. Some antioxidants e.g. flavonoids may also complex iron ions (Głód, Kaczmarski, \& Baumann, 2006). Additionally, the presence of hydrogen peroxide may lead to the generation of hydroxyl radicals (Garedew, Schmolz, \& Lamprech, 2003). All together, the TAPOH values depend on many parameters and substances present in the sample what may be inconvenient in some measurements. However, similar reactions are found in the human body. Therefore, the TAP values related to the hydroxyl radical better describe the truly occurring reactions between radicals and antioxidants, which run in living organisms. Differences among TAPOH values of that five honeys are smaller than those among TAPFCR, $A^{4} S^{450}$ or TAPDPPH because strong hydroxyl radicals react not only with strong antioxidants but also with such weak ones as sugars whose concentrations in all honeys are similar.

Electroanalytical techniques, particularly voltammetric, are used to study oxidants and antioxidants (Głód, Kiersztyn, \& Piszcz, 2014). To eliminate the capacitive currents and decrease the limit of detection, the measurements were performed using differential pulse voltammetry (DPV), but these methods are suitable for pure compounds. The TAP measure of real (for 
example honeys) samples can be the surface area (charge) under the voltammetric curve. A significant drawback of this method was the independence of the results on the potentials at which the reactions were carried out. Głód, Kiersztyn, \& Piszcz (2014) proposed the new TAPDPV measure, the surface area under the voltammetric curve in which the abscissa is the exponent of the potential measured in relation to the reduction potential of the hydroxyl radical. TAPDPV is directly proportional to the antioxidant concentration and inversely proportional to its redox potential. As in the previous measurements, the buckwheat honey was characterized by the strongest antioxidant properties while the acacia honey by the weakest (Fig. 3).

As mentioned, the electrochemical method allows the direct measurement of antioxidative activities (TAPs) and has been suggested to use the total surface area of all antioxidants recorded on the HPLC chromatogram obtained with amperometric detector, (Wantusiak, Piszcz, \& Głód, 2012). It is considered to be a major advantage of electrochemical detection in HPLC in comparison to the voltammetric methods. Due to the presence of large convection current and lack of capacitive current in the HPLC-ED measurements the TAP detection limit measured using HPLC-ED assay is several orders of magnitude lower than the TAP detection limit measured using DPV assay.

Another advantage of these assays is that TAP can be related to various potentials of the working electrode, i.e. to the different antioxidant power and to different retentions, i.e. it can be separated on individual antioxidants or groups of antioxidants. In addition, as a measure of TAPED the sum of TAPs obtained at various potentials can be used (Piszcz et al., 2014). Reversed phase HPLC chromatograms of buckwheat honey, obtained at various potentials, are presented in Fig. 5. The increase of potential increases (sigmoidal relationship) chromatographic peaks and creates the new ones. This provides additional information on the antioxidant properties of the sample.

The higher the chromatographic peak, the greater is the concentration of the antioxi- dant. The stronger antioxidant, the lower is it oxidation potential. Chromatographic peaks at retention times of 4.9, 6.9, 16.4 minutes come from strong antioxidants whose concentrations are lower, confirmed by small chromatographic peaks heights, than the concentration of antioxidants that appear at higher potentials. On the other hand, peaks that appear at the potentials of $0.6,0.8$ and $1.0 \mathrm{~V}$ with retention times of 6.1 , 9.5 and 14.5 minutes have weaker antioxidative effects, but there may be greater concentrations.

HPLC chromatograms of the $1 \mathrm{mg} / \mathrm{ml}$ buckwheat honey obtained at different potentials are presented in Fig. 5. TAPED values depend on the used potential. Shapes of the curves (Fig. 4) are similar to the hydrodynamically obtained voltamograms. Buckwheat honey turned out to be characterized by the most powerful antioxidant properties at all investigated potentials. Very high TAPED values at higher potentials suggest that buckwheat honey contains many weak antioxidants. In general, all curves were similar. Therefore, the values of honey TAPED obtained with different potentials did not provide additional information on their antioxidant properties. TAPED turned out to be proportional to TAPOH (Fig. 11). Correlation did not pass through zero because TAPED was measured at $1.0 \mathrm{~V}$ while the reduction potential of hydroxyl radicals equalled $2.31 \mathrm{~V}$. In other words, hydroxyl radical reacted with such compounds as alcohols and sugars which were not oxidized electrochemically.

Potential $1.0 \mathrm{~V}$ was selected as the optimal value. At higher potentials, there was no additional electrochemical signals from the weaker antioxidants, and only an increase in the total surface area was observed. In addition, at the potential higher than $1.2 \mathrm{~V}$, a carbon electrode and water are oxidized, which makes the measurements impossible.

We devised new TAP measuring methods to be applied to the investigation of honey antioxidative activity. TAPED, TAPDPPH and TAPFCR were used to correlate the obtained results (Fig. 12). A linear correlation was found between TAPED tested using different potentials. 


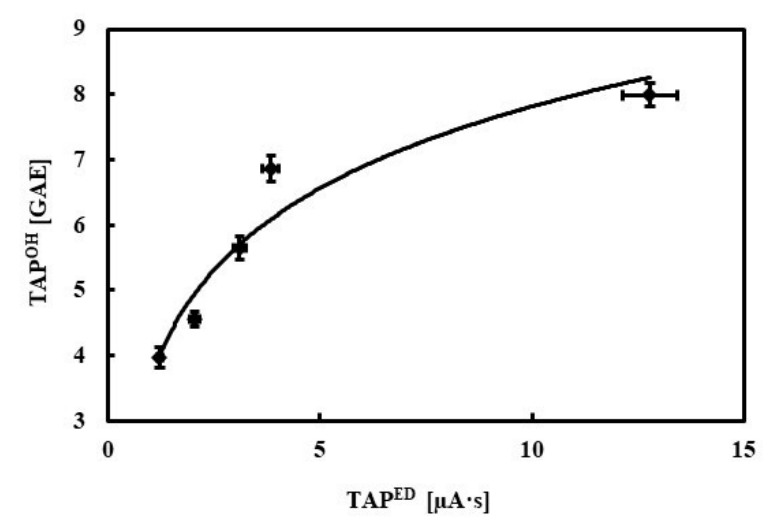

Fig. 11. Correlation between TAPOH and TAPED (1.0 V). Points correspond to honeys (acacia, multi-flower, linden, honeydew, buckwheat) according to their growing TAP values.

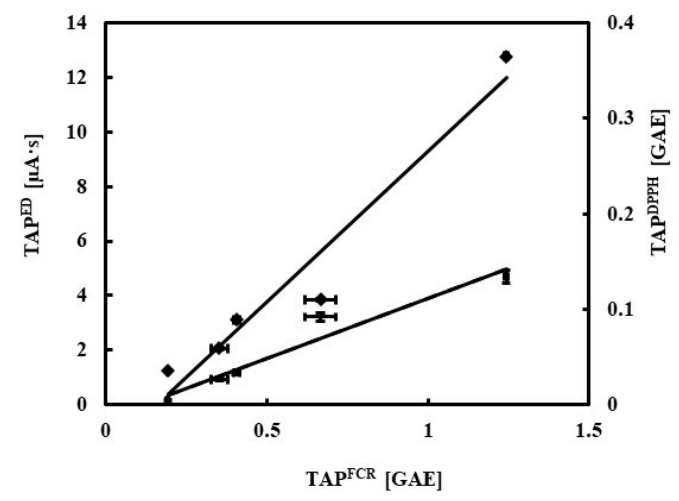

Fig. 12. Correlation between $\operatorname{TAP}^{E D}(1.0 \mathrm{~V})(\diamond)$, TAPDPPH $(\square)$ and TAPFCR. Points correspond to honeys (acacia, multi-flower, linden, honeydew, buckwheat) according to their growing TAP values.

The smallest differences among the honeys was found for $\mathrm{TAP}{ }^{\mathrm{OH}}$, due to the very high reactivity of hydroxyl radicals. There was a correlation between TAP and the color of honey, in which crystalline and dark honey had higher TAP values than liquid and light honeys. The TAP values largely depended on the content of polyphenolic compounds. The buckwheat honey had the strongest antioxidant activity while the acacia honey the lowest one. The same effect was observed for the honeys from other countries and tested using other methods (Maurya et al., 2014; Gül, \& Pehlivan, 2018). The examined honeys were typical for Poland, and their antioxidative properties examined through TAPDPPH, TAPOH, TAPDPV, TAPED, TAPFCR and ABS 450 grew in the order of acacia, multi-flower, linden, honeydew and buckwheat. The same order was obtained for phenolic compounds and flavonoids concentrations and color (Wieczorek et al., 2014).

\section{ACKNOWLEDGMENTS}

This work was performed within the framework of research project no. 228/06/S of Siedlce University. We would like to thank M. Cendrowska and P. Wantusiak for their assistance in performing the experiments.

\section{REFERENCES}

Antony, S.M., Han, I.Y., Rieck, J.R., \& Dawson, P.L. (2000) Antioxidative effect of maillard reaction products formed from honey at different reaction times. Journal of Agricultural and Food Chemistry, 48(9), 39853989. http://dx.doi.org/10.1021/jf000305x

Arroyo-Curras, N., Rosas-Garcia, V.M., \& Videa, M. (2016). Substituent Inductive Effects on the Electrochemical Oxidation of Flavonoids Studied by Square Wave Voltammetry and Ab Initio Calculations. Molecules, 27(11), 1422. https://doi.org/10.3390/molecules21111422

Bertoncelj, J., Doberšek, U., Jamnik, M., \& Golob, T. (2007). Evaluation of the phenolic content, antioxidant activity and colour of Slovenian honey. Food Chemistry, 105(2), 822-828, https://doi. org/10.1016/j.foodchem.2007.01.060

Bogdanov, S., Jurendic, T., Sieber, R., \& Gallmann, P. (2008). Honey for Nutrition and Health: A Review. Journal of the American College of Nutrition, 276), 677-689. https://doi.org/10.1080/07315724.2008. 10719745

Brand-Williams, W., Cuvelier, M.E., \& Berset, C. (1995). Use of a free radical method to evaluate antioxidant activity. (Lebensmittel-Wissenschaft \& Technologie), LWT - Food Science and Technology, 28(1), 25-30. https://doi.org/10.1016/S0023-6438(95)800085

Cheung, L.M., Cheung, P.C., \& Ooi, V.E.C. (2003). Antioxidant activity and total phenolics of edible mushroom extracts. Food Chemistry, 87(2), 249-255. 
https://doi.org/10.1016/S0308-8146(02)00419-3

Doménech-Carbó, A., Gavara, R., Hernández-Muñoz, P., \& Domínguez, I. (2015). Contact probe voltammetry for in situ monitoring of the reactivity of phenolic tomato (Solanum lycopersicum L.) compounds with ROS. Talanta, 144, 1207-1215, https://doi. org/10.1016/j.talanta.2015.07.092

Doménech-Carbó, A., Ibars, A.M., Prieto-Mossi, J., Estrelles, E., Doménech-Carbó, M.T., Ortiz-Miranda, A.S., Martini, M., \& Lee, Y. (2017). Access to Phylogeny from Voltammetric Fingerprints of Seeds: the Asparagus Case. Electroanalysis, 29(2), 643-650. https://doi.org/10.1002/elan.201600588

Elad, Y. (1992). The use of antioxidants (free radical scavengers) to control grey mould (Botrytis cinerea) and white mould (Sclerotinia sclerotiomm) in various crops. Plant Pathology, 47(4), 417-426. https://doi. org/10.1111/j.1365-3059.1992.tb02436.x

Garedew, A., Schmolz, E., \& Lamprech, I. (2003). The antimicrobial activity of honey of the stingless bee Trigona spp. Journal of Apicultural Science, 471), 37-49. http://www.jas.org.pl/The-antimicrobialactivity-of-honey-of-the-stingless-bee-i-Trigonaispp-,0,145.html

Głód, B.K., Czapski, G.A., \& Haddad, P.R. (2000). Application of high-performance liquid chromatography to the investigation of free radical reactions in biological systems. TrAC Trends in Analytical, 198), 492-497. https://doi.org/10.1016/S0165-9936(00)00018-2

Głód, B.K., Haddad, P.R., \& Alexander, P.W. (1992). Potentiometric detection of carboxylic-acids and inorganic anions in ion-exclusion chromatography using camphorsulphonic acid as eluent. Journal of Chromatography, 589(1-2), 209-214. https://doi. org/10.1016/0021-9673(92)80024-0

Głód, B.K., Kaczmarski, K., \& Baumann, M.H. (2006). Application of Mass Spectrometry to the Determination of Total Antioxidant Potential. Chemia Analityczna (Warsaw), 57, 51-64.

Głód, B.K., Kiersztyn, l., \& Piszcz, P. (2014). Total anti- oxidant potential assay with cyclic voltammetry and/ or differential pulse voltammetry measurements. Journal of Electroanalytical Chemistry, 719, 24-29. https://doi.org/10.1016/j.jelechem.2014.02.004

Głód, B.K., Piszcz, P., Czajka, K., \& Zarzycki, P.K. (2011). A new total antioxidant potential measurements using RP-HPLC assay with fluorescence detection. Journal of Chromatographic Science, 49(5), 401-404. https://doi.org/10.1093/chromsci/49.5.401

Gül, A., \& Pehlivan, T. (2018). Antioxidant activities of some monofloral honey types produced across Turkey. SaudiJournal of Biological Sciences, 25(6), 10561065. https://doi.org/10.1016/j.sjbs.2018.02.011

Hoyos-Arbeláez, J., Vázquez, M., \& Contreras-Calderón, J. (2017). Electrochemical methods as a tool for determining the antioxidant capacity of food and beverages: A review. Food Chemistry, 221, 1371-1381. https://doi.org/10.1016/j.foodchem.2016.11.017

Junie, L.M., Vică, M.L., Glevitzky, M., \& Matei, H.V. (2016). Physico-chemical characterization and antibacterial activity of different types of honey tested on strains isolated from hospitalized patients. Journal of Apicultural Science, 60(1), 5-17. https://doi. org/10.1515/jas-2016-0013

Masek, A., Chrzescijanska, E., \& Zaborski, M. (2014). Antioxidative Properties of Silymarin, 7-aminoflavone, Neohesperidin Dihydrochalcone and Trihydroxyethylenorutin Studied by the Electrochemical Methods. International of Journal of Electrochemical Science, 912), 7875-7889. http://www.electrochemsci.org/papers/vol9/91207875.pdf

Maurya, S., Kushwaha, A.K., Singh, S., \& Singh, G. (2014). An overview on antioxidative potential of honey from different flora and geographical origins, Indian Journal of Natural Products and Resources, 5(1), 9-19. http://nopr.niscair.res.in/handle/123456789/27471

Ortiz-Miranda, A.S., Koenig, P., Kahlert, H., Scholz.

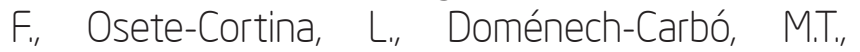
Doménech-Carbó, A. (2016). Voltammetric analysis 


\section{J. APIC. SCLI. VOL. 63 ND. 1 2019}

of Pinus needles with physiological, phylogenetic, and forensic applications. Analytical and BioanaIytical Chemistry, 408(18), 4943-4952. https://doi. org/10.1007/s00216-016-9588-7

Piszcz, P., Woźniak, M., Asztemborska, M., \& Głód, B.K. (2014). Comparative Analysis of Antioxidative Activity of Flavanoids Using HPLC-ED and Photometric Assays. Food Analytical Methods, 7, 1474-1480. https://doi.org/10.1007/s12161-013-9776-4

Piszcz, P., Zurawski, K., \& Głód, B.K. (2014). Application of HPLC to Study the Reaction of Free Radicals with Antioxidants and/or Toxins. Journal of Chemistry, Article ID 385908, http://dx.doi. org/10.1155/2014/385908

Pontis, J.A., Mendonça Alves da Costa, L.A., Reis da Silva, S.J., \& Flach, A. (2014). Color, phenolic and flavonoid content, and antioxidant activity of honey from Roraima, Brazil. Food Science and Technology, 34(1), 69-73. http://dx.doi.org/10.1590/S010120612014005000015

Raz, N., \& Daugherty, A.M. (2018). Pathways to Brain Aging and Their Modifiers: Free-Radical-Induced Energetic and Neural Decline in Senescence (FRIENDS) Model - A Mini-Review. Gerontology, 64(1), 49-57. https://doi.org/10.1159/000479508

Sharan, R.N., Odyuo, M.M., \& Purkayastha, S. (2011). Oxygen Free Radicals and Their Biomedical Implications: A Mini Review. Mini-Reviews In Organic Chemistry, 8(4), 372-376. https://doi. org/10.2174/157019311797440344

Singleton, V.L., Orthofer, R., \& Lamuela-Raventós, R.M. (1999). Analysis of total phenols and other oxidation substrates and antioxidants by means of Folin-Ciocalteu reagent. Methods in Enzymology 299(1), 152-178. https://doi.org/10.1016/S00766879(99)99017-1

Smirnov, A.I. (2017). Electron Spin Resonance In Food Science, Chapter 6 - Electron Paramagnetic Resonance Spectroscopy to Study Liquid Food and Beverages. (pp. 83-109). Cambridge, Massachusetts: Academic Press, https://doi.org/10.1016/B978-0-12-

\section{8-4.00006-4}

Sužnjević, D.Ž., Pastor, F.T., \& Gorjanović, S.Ž. (2015). DC polarographic examination of $\mathrm{Hg}^{2+}$ reduction applicability to antioxidant activity determination. Electrochimica Acta, 168, 240-245. https://doi. org/10.1016/j.electacta.2015.04.008

Wantusiak, P.M., Piszcz, P., \& Głód, B.K. (2012). A Fast and Simple Method for the Measurement of Total Antioxidant Potential and a Fingerprint of Antioxidants, Journal of Chromatographic Science, 5010), 909-913. https://doi.org/10.1093/chromsci/bms089

Waś, E., Szczęsna, T., Rybak-Chmielewska, H., Teper, D., Jaśkiewicz, K. (2017). Application of HPLC-DAD Technique for Determination of Phenolic Compounds in Bee Pollen Loads. Journal of Apicultural Science, 67(1), 153-162. https://doi.org/10.1515/jas2017-0009

Wieczorek, J., Pietrzak, M., Pomianowski, J., \& Wieczorek, Z. (2014). Honey as a source of bioactive compounds. Polish Journal of Natural Sciences, 29(3), 275-285. http://www.uwm.edu.pl/polish-journal/ sites/default/files/issues/articles/wieczorek_et_ al._2014.pdf

Wilczyńska, A. (2010). Phenolic content and antioxidant activity of different types of polish honey. Polish Journal of Food and Nutrition Sciences, 60(4), 309313. http://journal.pan.olsztyn.pl/fd.php?f=1266

Wróblewska, A., Warakomska, Z., \& Koter, M. (2006). Pollen analysis of bee products from the North-Eastern Poland. Journal of Apicultura/ Science, 501), 71 83. http://www.jas.org.pl/Pollen-analysis-of-beeproducts-from-the-North-Eastern-Poland,0,82.html

Wróblewska, A., \& Stawiarz, E. (2004). Pollen spectrum of some honeys from Opatów vicinity. Journal of Apicultura/ Science, 48(2), 23-33. http://www.jas. org.pl/Pollen-spectrum-of-some-honeys-r-nfromOpatow-vicinity,0,41.html 